Indexaciones: Repositorio de Revistas UCR, DIALNET, Latindex, REDALYC Directorio y recolector de recursos digitales del Ministerio de Cultura de España, Directory of Open Access Journals.

Diálogos Revista Electrónica de Historia ISSN 1409-469X. Número especial 2008. Dirección web: http://historia.fcs.ucr.ac.cr/dialogos.htm

\section{Democracia, crisis del paradigma liberacionista y anticomunismo en la campaña electoral de $1970 .^{1}$}

M.Sc. Mercedes Muñoz Guillén

$1 \quad$ Con este trabajo se completa la presentación de los resultados obtenidos alrededor de la línea de investigación: el anticomunismo en las campañas electorales de la década del 60 . El antecedente inmediato de éste último esfuerzo está constituido por el artículo: "DEMOCRACIA Y GUERRA FRÍA EN COSTA RICA: EL ANTICOMUNISMO EN LAS CAMPAÑAS ELECTORALES DE LOS AÑOS 1962 Y 1966”. 
"llegar a sentar las bases de un partido de lucha política. De un partido cuya ideología, basada en los principios democráticos se adecuara rigurosamente a los datos de nuestra realidad nacional y de nuestra evolución social y política y garantizara así el progreso de nuestra nacionalidad ajustado a la evolución universal de las ideas políticas, así como a las características de nuestra particular historia. Queríamos crear una organización que defendiera un conjunto de principios, no a un hombre. Un partido con una finalidad". Centro para el Estudio de los Problemas Nacionales. 1940

"En Costa Rica poco a poco tendrá que ir desapareciendo el personalismo en política, para dar paso a los partidos permanentes, ideológicos”. Representante Fernando Baudrit Solera. Asamblea Nacional Constituyente. 1949

"Cuando un pueblo elige Presidente a un hombre sin ideas, sin récord de estadista, sin planes, cuando lo elige sólo porque se le reconoce que 'es muy bueno', algo debe andar mal en ese país; algo debe estar descompuesto; alguna falla grave debe estar carcomiendo la estructura de la nacionalidad”. Representante. Rodrigo Facio Brenes. Asamblea Nacional Constituyente. 1949.

"Después de todo parece que a una gran cantidad de costarricenses les gustan más la calumnia, la injuria y el escándalo, que le exposición de ideas y de programas en una campaña electoral”. Daniel Oduber Quiroz. 1966

\section{Introducción}

En la campaña electoral de 1958, José Figueres Ferrer -si ningún tipo de reparopresentaba al PLN como el prototipo del partido permanente e ideológico.

Diez años después, en un documento preparado con la finalidad de ser discutido en el Congreso Ideológico a celebrarse en 1969, se afirmó: “(...) el PLN no ha existido como Partido permanente e ideológico (...) nuestra tarea inmediata es alcanzar esa meta, por encima de los viejos y de los nuevos personalismos. Hemos creado la idea de un Partido con esas características, pero el Partido permanente e ideológico no ha existido en la realidad”. ${ }^{2}$

Pero, la situación del PLN tiene estrecha relación con un contexto más amplio. En efecto, cuando se examinan los rasgos definitorios de la vida política entre 1948 y 1968, se constata lo

2 Véase el documento “Reestructuración del Partido Liberación Nacional”. Año 1968. En la página electrónica del Partido Liberación Nacional: http://www.pln.or.cr 
siguiente: a) Un dominio irrestricto e injustificado de la vida nacional por cuatro o cinco personajes, a través de 30 años en unos casos y de 20 años en otros., b) La división de los ciudadanos en dos sectores, separados por la Guerra de Liberación Nacional, c) La ausencia de Partidos permanentes e ideológicos, que respondan a los más importantes intereses de la nación y d) En esos 20 años no han podido organizarse ni manifestarse, y por tanto no han participado efectivamente del poder, los sectores sociales mayoritarios. ${ }^{3}$

Si bien es cierto, en el Manifiesto de Patio de Agua y en la Carta Ideológica de la Juventud, se reconoce la necesidad de transitar de un partido de corte personalista hacia uno permanente e ideológico y son coincidentes en los medios para alcanzar ese propósito, a saber: 1) La existencia de un ideario, doctrina o ideología, 2) La presencia de una organización dentro de la cual debe realizarse la vida plena del movimiento y 3) La organización de la base social, sus planteamientos se ubican más allá de ese fin y esos medios.

Ellos apelan más bien a una crisis general del paradigma liberacionista, evidenciado en hechos como los siguientes:

- “(...)el desarrollo económico logrado en los últimos años ha beneficiado desproporcionadamente a las clases adineradas, habiéndose producido así un progreso socialmente desequilibrado".

- "Una enorme mayoría del pueblo. costarricense sufre esas condiciones de privación, mientras una minoría que retiene al máximo de privilegios y otros grupos que han logrado mejorar sus niveles de vida, son insensibles a las situaciones en que viven esas mayorías nacionales." ${ }^{4}$

En ese sentido, plantean la necesidad de "introducir aquellas reformas que permitan, al máximo, el desarrollo económico orientado socialmente, de suerte que sus beneficios fluyan primordialmente hacia los que hoy sufren explotación y miseria”. ${ }^{5}$

3 Ibid., http://www.pln.or.cr

4 Ver "Patio de Agua. Manifiesto Democrático para una Revolución Social”. Año 1968.En la página electrónica del Partido Liberación Nacional: http://www.pln.or.cr

5 Ibid., http://www.pln.or.cr 
En este artículo, en primer lugar, se examinan varios aspectos interrelacionados: la propaganda del Partido Unificación Nacional (PUN) que parte de la igualdad Manifiesto de Patio de Agua= Comunismo, la defensa que esgrime Liberación Nacional, las razones que tiene Oduber para calificar el Manifiesto como una proclama de "extrema izquierda" y los antecedentes de ese proceder. Además se aborda el siguiente problema: ¿en qué medida el Manifiesto y la Carta pueden considerarse como proclamas de "extrema izquierda"?. Mientras que en el segundo acápite, el interés recae en explicar, por un lado, por qué y cómo el Partido Liberación Nacional en el trayecto del Manifiesto a la Segunda Carta Fundamental optó finalmente por el Movimiento Costa Rica Libre en calidad de aliado y, por otro lado, las implicaciones de ese acercamiento en relación con su postura ideológica respecto al comunismo criollo.

I. Patio de Agua, la Carta Ideológica de la Juventud Liberacionista y el Congreso ideológico del Partido Liberación Nacional de 1969: rumbo a las elecciones de 1970.

Durante la campaña electoral de 1969-1970, la propaganda de Unificación Nacional englobó, lisa y llanamente, en la categoría de “comunismo" los planteamientos contenidos en el documento "Patio de Agua. Manifiesto Democrático para una Revolución Social".

Para contrarrestar esa campaña, Figueres advirtió en un campo pagado en el periódico La Nación, cuyo título es "UN MENSAJE A LOS COSTARRICENSES DECENTES DE TODOS LOS PARTIDOS”, que ni “Patio de Agua” ni la "Encuesta de Santa Cruz", forman parte del programa oficial del PLN. (La Nación, 16 de noviembre de 1969, p. 45).

Unificación Nacional, en virtud del pronunciamiento de José Figueres Ferrer más bien intensificó esa línea e hizo circular consignas como las siguientes: "EL COMUNISMO APOYA 'PATIO DE AGUA' Y PROPONE UNA ALIZANZA AL FIGUERISMO”(Ibid., 25 de noviembre de 1969), "LIBERACION APLICA PATIO DE AGUA IMPONIENDO AL PARTIDO DE LOS COMUNISTAS (Ibid., 28 de noviembre de 1969), "YA APARECIERON LAS GUERRILLAS ROJAS ALENTADAS POR COMUNISTAS Y FIGUERISTAS FIRMANTES DE 'PATIO DE AGUA' “(Ibid., 3 de enero de 1970, p.5), entre muchas otras. 
Uno de los firmantes del Manifiesto fue Enrique Obregón Valverde ${ }^{6}$, quien junto con Marcial Aguiluz se había separado del PLN antes del proceso eleccionario de 1962, ostentando luego la condición de candidato a la Presidencia por el Partido Acción Democrática Popular, movimiento éste que recibió el apoyo abierto de Vanguardia Popular. Otro figura política que estampó su firma fue Luís Alberto Monge Álvarez, él que, según Solís (1992), representaba en asocio con Daniel Oduber el “ala izquierda” del Partido Liberación Nacional.

Oduber, por su parte, guardó prudente distancia en relación con el "Manifiesto Democrático para una Revolución Social”(Enero de 1968), extendiendo ésta también a "la Carta Ideológica de la Juventud Liberacionista” (Mayo de 1968) y a otros escritos surgidos en América Latina en esa época. Las razones esgrimidas por él pueden resumirse de la siguiente manera:

a) “...todos los documentos citados caen a veces en contradicciones internas y son culpables de la utilización de frases y conceptos retóricos, muy comunes en el socialismo romántico de los últimos treinta años”,

b) "En la medida en que nosotros hagamos proclamas de extrema izquierda, poco serias e irrealizables, en la misma medida estaremos fortaleciendo las derechas. Los errores verbales de los partidos populares o de la izquierda democrática, han sido la causa del refortalecimiento de los grupos militares y de la miopía de algunos grupos económicos de nuestro Continente",

c) "Si la izquierda democrática no estudia y no hace planteamientos doctrinarios y programáticos serios, dará argumentos fuertes a comunistas y derechistas, los que, en definitiva, vendrían a ser los que disputaran la hegemonía política y doctrinaria del país”,

d) "Estudiar es la tarea de Liberación Nacional. La Juventud Costarricense ya no se deja engañar, y exige de sus dirigentes posiciones claras y definidas, basadas en la investigación y el estudio. Llamémosla a

$6 \quad$ Además, de los 57 restantes pueden citarse, entre otros: a Alfonso Carro Zúñiga, Isaac Felipe Azofeifa, Fernando Volio Jiménez y José Luís Vega Carballo como adherentes del documento comentado.

7 Ver Solis, Manuel. Costa Rica: ¿Reformismo socialdemócrata o liberal?. FLACSO. San José, Costa Rica. 1992. págs. 339-347. 
estudiar con nosotros, y preparémosla para la acción política seria y para las ideas revolucionarias dentro de lo que hoy es esta Revolución Posible que el país exige”. ( Las Itálicas son nuestras)

Además, Oduber afirmó: "He notado con tristeza que muchas de las ideas debatidas recientemente en Costa Rica, ignoran deliberadamente las ciencias económicas contemporáneas y se limitan a contemplar la injusticia social y a la proposición de soluciones un tanto románticas.”9

Su conclusión, en lo que refiere a los planteamientos de Patio de Agua y de la Juventud Liberacionista - a la luz de todas las apreciaciones anteriores - es la siguiente: "no deben ser entendidos como programas específicos de Gobierno, sino apenas como declaraciones generales de principios." ${ }^{10}$ Y agrega: "Por eso, asustarse ante ellos, o ante los comentarios de mala fe que se han hecho sobre ellos, es como asustarse de lo que digan los libros sobre política que uno pueda leer. Tenerle miedo a las ideas es dejarle el campo libre a los comunistas para que sean ellos los que den ideas a nuestra juventud" ${ }^{11}$, con estas afirmaciones se adelantó a la campaña de Unificación y facilitó un argumento útil al propio Figueres.

La corriente que quiere abrirse paso en Liberación Nacional "intenta legitimarse haciendo una equivalencia entre sus tesis de 1960-1962 con las tesis PSD (Partido Social Demócrata) en 1945; ellos se presentan como sus continuadores”. ${ }^{12}$ Y está conformada, fundamentalmente, por intelectuales y estudiantes.

En la campaña electoral de 1966, Manuel Mora Valverde al caracterizar, por un lado, a Daniel Oduber y, por otro, a la Juventud Liberacionista, señaló: “...no es el señor Oduber hombre capaz de mantener con firmeza sus ideas - que están muy lejos del comunismo- porque 8 Cfr. Oduber, Daniel. Apuntes para un Congreso Ideológico del Partido Liberación Nacional. En la página electrónica del Partido Liberación Nacional: http: // www. pln. or. cr/.

9 Ibid., página electrónica del Partido Liberación Nacional: http: // www. pln. or. cr/.

10 Ibid., página electrónica del Partido Liberación Nacional: http://www.pln.or.cr

11 Ibid., página electrónica del Partido Liberación Nacional: http:// www.pln.or.cr/

12 Ibid., página electrónica del Partido Liberación Nacional: http:// www.pln.or.cr/ 
siempre lo hemos visto actuar de acuerdo con sus conveniencias. Sabe bailar en la cuerda floja y sólo las fuerzas progresistas de su partido, que son importantes y están integradas especialmente por jóvenes de la nueva generación, podrán impedirle que, como gobernante, se entregue a las derechas del país o se someta a la presión de Washington”"13.

Mora Valverde respecto a la Juventud, enfatizó : "Públicamente por ejemplo, se le enfrentaron al propio Oduber hace algún tiempo, cuando Oduber quiso impedirles a los jóvenes que suscribieran la llamada declaración de San José elaborada por varios Partidos de la Izquierda democrática de América Latina”. ${ }^{14}$

El enfrentamiento descrito por Mora, resulta difícil de explicar cuando se consideran los siguientes hechos:

Primero, "en 1959, bajo la influencia (de la Revista) Combate se funda la 'Juventud Liberacionista'. En su congreso de 1960, la Juventud reproduce literalmente las reivindicaciones de Combate y se empieza a perfilar como una corriente crítica, que proclama el regreso a las raíces socialdemócratas de la organización. Los jóvenes son alentados por Oduber y Monge(... )${ }^{15}$

Segundo, "si se toma como parámetro las publicaciones e intervenciones públicas de este grupo, lo que caracteriza a este sector es una identificación más directa con el aprismo...En el centro del dilema político nacional, como un caso particular del gran dilema latinoamericano , estarían los impedimentos a la modernización y la industrialización interpuestas por las 'oligarquías feudales terratenientes'...En el discurso que divulgan Monge y Oduber, el atraso(...) es(...)el producto de un orden precapitalista en que se conciliarían los intereses de las oligarquías agrarias con las formas tradicionales de presencia del imperialismo, tipificados por los enclaves mineros y agrícolas". ${ }^{16}$

13 Cfr. Mora Valverde, Manuel. Discursos (1934-1979), Editorial Presbere. Costa Rica. 1980. p. 581.

14 Ibid., p.582.

15 Cfr. Solis, Manuel. Op .cit., p. 344.

16 Ibid., págs 340-341. 
Tercero, Marcelo Prieto Jiménez (1971), en su ensayo El pensamiento de Daniel Oduber recalca la convergencia de tres corrientes ideológicas en él, a saber: "la socialdemocracia europea, el pensamiento liberal norteamericano, y el aprismo peruano" ${ }^{17}$ Éste último - en palabras de Prieto- “( ...) ha desempeñado un papel importantísimo en la génesis de los movimientos y partidos de izquierda democrática en América Latina. Realizó la importante tarea de adaptar las tesis y principios del socialismo europeo a la realidad política, social y económica latinoamericana”. ${ }^{18}$

Cuarto, “en la campaña de 1965-1966, el PLN moviliza por última vez el paradigma antioligárquico" ${ }^{19}$ En ese proceso eleccionario, la propaganda de Unificación Nacional hace referencia a la etapa en la que Oduber criticaba duramente, desde la tribuna de la Revista Combate, a los Estados Unidos. ${ }^{20}$

Si bien la actitud de Oduber podría ser interpretada como un esfuerzo para impedir ya la añeja estratagema de los opositores políticos del PLN, de asociar los planteamientos de éste con el "comunismo", no puede omitirse que sus reservas tienen estrecha relación con el contexto externo imperante, esto es, la redefinición de la política norteamericana hacia América Latina .

En efecto, debe tenerse en cuenta, tal y como señala Monteforte Toledo(1972) que“ En marzo de 1965, al cumplirse el tercer aniversario de la Alianza para el Progreso, Johnson pronunció un discurso en el cual ni siquiera mencionaba como impedimento para otorgar ayuda a los gobiernos latinoamericanos su origen cuartelario, su carácter dictatorial o su línea reaccionaria...Tres día más tarde fue nombrado subsecretario de Estado para Asuntos Latinoamericanos Thomas Mann de larga trayectoria como 'experto’ en la región, donde había ingeniado no pocos cuartelazos 'preventivos' y colaborado en la primera línea de invasión de

17 Prieto, Marcelo. El pensamiento de Daniel Oduber. Año 1971. En la página electrónica del Partido Liberación Nacional: http://www.pln.or.cr/daniel/pdaniel.htm

18 Ibid., página electrónica del Partido Liberación Nacional: http://www.pln.or.cr

19 Cfr. Solis, Manuel. Op .cit., p. 359.

20 El campo pagado por el PUN tiene por título: “TÁCTICAS COMUNISTAS” y es utilizado para señalar que el PLN miente al publicar una foto de Oduber con Kennedy. Véase La Nación, 5 de febrero de 1966, p. 23. 
Guatemala. Fue él quien se encargó de hacer participé de la línea dura y del énfasis militar en la política continental. En uno se sus primeros actos oficiales advirtió a los embajadores de los Estados Unidos en Latinoamérica convocados a reunión especial en Washington, que el país dejaría de ocuparse en promover la libertad y la democracia, y que debía circunscribirse ' a los intereses inmediatos de seguridad nacional, tales como la protección de los intereses norteamericanos y la resistencia contra el comunismo. Todas estas ideas se fueron amalgamando hasta constituirse lo que ha dado a llamarse la 'la doctrina Johnson'. A su sombra se produjeron desde finales de 1963 los cuartelazos de Honduras, Ecuador, Brasil, Bolivia, Panamá y Perú(...) las tropas norteamericanas ocuparon la República Dominicana, tan impunemente como en los tiempos del 'gran garrote'. ” 21

Figueres-quien según sus palabras- junto con Rómulo Betancourt y el ex Gobernador Luís Muñoz Marín se constituyeron, en Washington, en un comité informal y de asesoramiento, durante la invasión a República Dominicana, justificó la acción militar de los Estados Unidos en los siguientes términos:

"Hubo un momento en que estuvieron en peligro centenares de norteamericanos, tanto ciudadanos privados como funcionarios de gobierno. Los militares dominicanos manifestaron que no podían garantizar sus vidas...No existía una fuerza internacional capaz de moverse rápidamente. En tales circunstancias, ningún gobierno, y menos el de una gran potencia, puede abstenerse de entrar en acción (...) Luego pareció, a juicio de los observadores norteamericanos, que los dirigentes comunistas podían tomar el liderato de la revuelta popular (...) Conviene recordar que ya entonces el mundo estaba inundado de noticias, probablemente difundidas por la maquinaria del trujillato, en las cuales se llamaba comunistas a los rebeldes y se llamaba 'Leales' a los trujillistas”. ${ }^{22}$

Dado el contexto externo descrito, asumir nexos con el Aprismo o con corrientes políticas que hicieran suyas la "orientación claramente antiimperialista y antioligárquica"23 que 21 Ver Ver Monteforte, Mario. Centroamérica. Subdesarrollo y Dependencia. Instituto de Instituto de Investigaciones Sociales. Universidad Autónoma de México. Tomo II. México. 1972. págs. 213-214.

22 Cfr. José, Figueres. Escritos de José Figueres Ferrer. Política, Economía y Relaciones Internacionales. EDUNED-Fundación pro Centro Cultural e Histórico José Figueres Ferrer. San José, Costa Rica. 2000. p. 557.

23 Véase Prieto, Marcelo. Op cit., en la página electrónica del Partido Liberación Nacional: http: // www. pln. or. $\mathrm{cr} /$. 
éste defendía, era - a juicio de Oduber- más que arriesgado. Además, su cautela obedecía a la radicalización experimentada por la sociedad costarricense como producto de la guerra fría, reflejada en un discurso anticomunista que había penetrado en amplios sectores de la población y que tenía como unos de sus destinatarios centrales al PLN.

Sin embargo, en qué sentido, según su dicho, "las declaraciones generales de principios" contenidas en el Manifiesto de Patio de Agua y en la Carta Ideológica de la Juventud Liberacionista, podrían ser interpretadas como proclamas de "extrema izquierda".

El Manifiesto de Patio de Agua y La Carta Ideológica de la Juventud Liberacionista: ¿proclamas de extrema izquierda?

El Manifiesto de Patio de Agua parte del siguiente diagnóstico:

- "Una enorme mayoría del pueblo. costarricense sufre ... condiciones de privación, mientras una minoría que retiene al máximo de privilegios y otros grupos que han logrado mejorar sus niveles de vida, son insensibles a las situaciones en que viven esas mayorías nacionales, sin tomar debidamente en cuenta el derecho que les asiste a reclamar su justa participación en aquellos altos valores".

- "Causas fundamentales de que esa situación prevalezca son el bajo nivel de desarrollo humano y económico y una organización social injusta y deficiente, unida a un proceso político generalmente dominado por uno clase privilegiada, que, de hecho, pone a su servicio esa organización y ese proceso".

- "El régimen democrático es el más adecuado a la dignidad del hombre, pero sólo puede entenderse por democrático un régimen en el que el poder político está en manos del pueblo a través de partidos que representen auténticamente a las grandes mayorías nacionales; la democracia cuenta con los recursos para desarrollar la economía y distribuir equitativamente la riqueza a fin de eliminar la miseria económica, cultural y espiritual en que viven esas grandes mayorías, hoy sometidas a servir primordialmente los intereses de las clases poderosas.”

- "Afirmamos que el desarrollo económico logrado en los últimos años ha beneficiado desproporcionadamente a las clases adineradas, habiéndose producido así un progreso socialmente 
desequilibrado. Creemos entonces indispensable introducir aquellas reformas que permitan, al máximo, el desarrollo económico orientado socialmente, de suerte que sus beneficios fluyan primordialmente hacia los que hoy sufren explotación y miseria.”24

La Revolución se entiende, en ese documento, como “ 'la ruptura con un sistema social que ya no garantiza el bien común y la instauración de un orden nuevo más apto para procurarlo'. La revolución debe ser un proceso acelerado, dirigido, profundo, integral e irreversible. Debe ser concebida y realizada en libertad a fin de que produzca más libertad". El carácter revolucionario de la proclama tiene estrecha relación con aspectos como los siguientes: a) "El mensaje surge en el seno del Partido Liberación Nacional; va dirigido a exigir, en todos sus cuadros, incluyendo a sus más altos dirigentes, un examen de conciencia, una rectificación de conducta, un retorno a la ruta inicial y una voluntad de misión histórica", b)” El mensaje ofrece un pensamiento político costarriqueñista para liberar al pueblo costarricense. Es la revolución social que surge de la historia patria y de su cultura. Aspira a realizar el destino de este pueblo” y c) ”El mensaje no está comprometido con ninguna escuela de pensamiento político sistemático y cerrado”. ${ }^{25}$

El Manifiesto se divide en cuatro grandes apartados, a saber:
A. PRINCIPIOS IDEOLOGICOS GENERALES.
B. ORIENTACIONES PROGÁMATICAS ESPECIFÍCAS.
C. INSTRUMENTOS DE ACCIÓN.
D. REQUISITOS ÉTICOS.

En relación con el diagnóstico reseñado más arriba - esbozado en el apartado relativo a los Principios Ideológicos Generales- el candidato presidencial José Figueres Ferrer no esquiva el problema de la miseria, pero lo hace depender tanto de la dinámica del comercio exterior como de resultados no deseados asociados al patrón de desarrollo impulsado en el país

24 Véase "Patio de Agua. Manifiesto Democrático para una Revolución Social”. Año 1968.En la página electrónica del Partido Liberación Nacional: http: // www. pln. or. cr/.

25 Ibid., página electrónica del Partido Liberación Nacional: http: // www. pln. or. cr/. 
y también de la explosión demográfica. Él, entre otros, hace los siguientes señalamientos:

- "Nuestro aparato económico es hoy como el motor de un jeep alemán de tres cilindros. Uno está casi muerto. Lo forman los pobres de las ciudades, los pequeños agricultores arruinados, y los jornaleros campesinos de medio sueldo, todo lo que podría llamarse la población sumergida... Los otros dos cilindros ,activos, se componen de buenos operarios, gran parte de la clase media, y los propietarios prósperos; todos aquellos para quienes se iluminan las vitrinas de las tiendas”. ${ }^{26}$

- "La década de los 60 en Costa Rica, década de crisis ha engendrado uno de los peores males sociales: el desempleo...Los precios del café y del cacao cayeron desde 1958. El rendimiento de las fincas bajo. Los finqueros redujeron planillas para mermar gastos, y los que pudieron adoptaron métodos técnicos para economizar peones...Hoy, en café, un hombre con una bomba hace el trabajo de una cuadrilla de paleros. En las llanuras bajas, un tractorista desyerba terreno por cien macheteros. En las laderas antes destinadas a la agricultura manual .a medida que el maíz y el arroz retroceden avanza el jaragua, porque la ganadería de carne ocupa poca gente. En todo el país, el crecimiento loco de la población lanza al mercado de trabajo muchos más brazos de los que pueden colocarse, y aumenta el desempleo. Todo aumenta el desempleo". ${ }^{27}$

Oduber, por su parte, reconoce que: "La lucha social en el país fue casi exclusivamente en pro de las clases urbanas. Las próximas décadas deberán ver la adaptación de todos los programas sociales a los campos, a donde no han llegado todavía los beneficios del cambio. Aun los salarios mínimos legales -anteriores como concepto al Código de Trabajo-, no se respetan en los campos de Costa Rica, para no hablar ya de los beneficios mínimos de la seguridad social". ${ }^{28}$

Enfrentados a los problemas señalados, Figueres y Oduber encuadran sus planteamientos tanto en la línea de la "Revolución posible" como en las soluciones que ofrecen las "Ciencias Económicas”.

26 Cfr, Figueres, José. Op .cit., p. 237.

27 Ibid., 224

28 Véase Oduber, Daniel. Op cit., página electrónica del Partido Liberación Nacional: http: // www. pln. or. $\mathrm{cr} /$. 
El extremismo que dice Oduber puede ser predicado respecto al Manifiesto de Patio de Agua, posee un fuerte referente interno. En efecto, como bien señala Prieto:

“Toda persona que manifiesta su preocupación por los problemas sociales de Costa Rica, corre el riesgo inminente de ser calificado de comunista. Cualquiera que señale el régimen de explotación a que están sometidos amplios sectores, campesinos y obreros, se expone a que se le acuse de fomentar la lucha de ciases. El que apunta la necesidad de planificar la utilización de los recursos nacionales, o la urgencia de aplicar métodos más eficaces de redistribución de la riqueza, o la conveniencia de impedir la acumulación de tierras en pocas manos es de manera casi inmediata señalado como extremista. La acusación de comunista en Costa Rica trae tales perjuicios, que es uno de los instrumentos de control social más eficaces con que pueden contar los enemigos del cambio; paraliza la acción de las fuerzas progresistas, que en muchos casos se repliegan temerosas de estigmatización, y desprestigia ante el público cualquier movimiento que busque transformar el sistema social imperante.”29

Pero, aunque esto es innegable. El Manifiesto subraya puntos neurálgicos parcialmente asumidos o sistemáticamente postergados por la cúpula del PLN y los Gobiernos de ese partido. Por ejemplo, en cuanto a la política agraria, se afirma:

"La distribución de tierras baldías que están al margen de los beneficios de la civilización no es reforma agraria; ésta debe hacerse en tierras actualmente aptas para la producción y con vías de comunicación adecuadas." 30

Las orientaciones programáticas específicas contenidas en el Manifiesto, abarcan amplios campos de la realidad social, económica y política del país. Los instrumentos privilegiados para alcanzar las finalidades que se proponen, tienen estrecha relación con las siguientes dos áreas: a) Participación Popular y b) Partidos Políticos.

Respecto a la organización del pueblo se hacen planteamientos como los siguientes:

"La vigencia de la democracia exige que el sistema político esté estructurado de tal manera que los sectores populares tengan participación efectiva y constante en los órganos de decisión política en todos

29 Véase Prieto, Marcelo. Op cit., página electrónica del Partido Liberación Nacional: http: // www. pln. or. $\mathrm{cr} /$.

30 Véase "Patio de Agua. Manifiesto Democrático para una Revolución Social". Año 1968.En la página electrónica del Partido Liberación Nacional: http: // www. pln. or. cr/. 
sus niveles, mediante mecanismos adecuados de organización que les permita contribuir al desarrollo económico y social para beneficio de todos." ${ }^{31}$

\section{Mientras que sobre los Partidos Políticos se puntualiza:}

“El partido político por ser una de las formas más efectivas de participación popular, debe constituir el instrumento más eficaz de los sectores populares para ejercer el poder político a favor de sus intereses, ya sea controlando ese poder plenamente, o bien participando en él como sólida representación de una parte de los ciudadanos.”32

Los movimientos generados alrededor del Manifiesto como de la Carta Ideológica de la Juventud Liberacionista, son enjuiciados por un sector del Partido Liberación Nacional en los siguientes términos:

"La ausencia de un Partido permanente e ideológico ha llevado a algunos compañeros a realizar un meritorio esfuerzo por establecer las bases de lo que podría ser la definición ideológica del PLN en el Congreso de octubre de 1968. Declaramos nuestra solidaridad con esos movimientos y reconocemos que esa tarea es decisiva para el objetivo común de concretar nuestro anhelo: la fundación del Partido permanente e ideológico,... Coincidimos con esos movimientos en su crítica constructiva al PLN, por no haber tenido un contenido ideológico preciso. Es posible preguntarse: ¿qué hemos representado ideológicamente? ¿Un socialismo democrático? ¿Ideas socialdemócratas? ¿Un socialismo de Estado? ¿Un socialismo cristiano? ¿O un liberalismo social? Sin lugar a dudas, podríamos ubicar en esas etiquetas algunos de los actos parciales de nuestro Movimiento. Pero una clara definición en un sentido o en otro y, principalmente, haber transitado en forma constante por un camino programático determinado, eso no lo hemos tenido. Ordinariamente, y especialmente en funciones de Gobierno, cada liberacionista se ha guiado por ideas y por programas más o menos de hechura personal. Esto aconteció en las dos oportunidades en que se ejerció el poder dentro de la Constitución”. ${ }^{33}$

Ese mismo sector señala:

- “Veinte años después de la fecha en que surgió el Movimiento de Liberación Nacional hemos 31 Ibid., página electrónica del Partido Liberación Nacional: http: // www. pln. or. cr/.

32 Ibid., página electrónica del Partido Liberación Nacional: http: // www. pln. or. cr/.

33 Véase el documento “Reestructuración del Partido Liberación Nacional”. Año 1968. En la página electrónica del Partido Liberación Nacional: http: // www. pln. or. cr/. 
tenido y vivido el espíritu liberacionista, pero no hemos creado el PLN como organización política permanente, ideológicamente definida, y al servicio constante del pueblo. Se ha creado una “conciencia de Partido”, pero no al Partido mismo”.

- "La existencia de un Partido permanente e ideológico exige, en primer término, un ideario, una doctrina, una ideología... Además, un Partido permanente e ideológico requiere, como condición fundamental, una estructura, una organización dentro de la cual debe realizarse la vida plena del movimiento. Los líderes máximos deben sujetarse a los organismos partidistas, y deben actuar dentro de ellos... Y en tercer lugar, un Partido permanente necesita, como fundamento irrenunciable, organizar su base social”.

- No ha habido cambios en las estructuras económicas y sociales, capaces de transformar la situación agobiante de los sectores mayoritarios. En realidad, ningún problema nacional importante ha sido satisfactoriamente resuelto. Debemos preguntarnos: ¿en qué grado se han reducido la miseria, la ignorancia, las desigualdades económicas y sociales, la injusticia y la ineficacia de la acción política que sufren las mayorías?

- Solo la lucha contra el personalismo, en la medida que sea reducido a un nivel racional y natural, podrá crear las condiciones necesarias para organizar el Partido permanente e ideológico que se constituya en el representante de los grupos sociales que conforman la nación. Y solamente un Partido organizado sobre esas bases podrá ejecutar la política de cambios que creará la democracia sustantiva”. ${ }^{34}$

Paradójicamente, las formulaciones que, a juicio de Oduber, podían ser interpretadas como de "extrema izquierda", fueron incorporadas en las resoluciones del Congreso Ideológico celebrado en 1969. Este es el caso de los postulados relativos a la Reforma Agraria, pues allí se afirmó:

“Queremos en particular que la tierra esté efectivamente al alcance del que quiera trabajarla, y que no sea objeto de acaparamiento.”35

"El latifundio debe ser eliminado. El Partido ha de promover una política justa de reforma agraria para

$34 \quad$ Ibid., página electrónica del Partido Liberación Nacional: http: // www. pln. or. cr/.

35 Véase "Segunda Carta Fundamental del Partido Liberación Nacional. Marzo de 1969.En la página electrónica del Partido Liberación Nacional: http: // www. pln. or. cr/. 
alcanzar una distribución más equitativa de la tierra y un mayor incremento del ingreso nacional... Las tierras que no se mantengan en producción deben ser expropiadas y distribuidas entre quienes las pueden explotar, a fin de que cumplan su función social. La reforma agraria debe ir acompañada de un plan paralelo de educación y de salud para convertir al peón de hoy en el pequeño empresario agrícola de mañana. También debe ir a la par de un plan de creación de mercados regionales, de asistencia, de crédito, de seguros sobre las cosechas y, de manera especial, de fomento de las cooperativas agrícolas.”36

En igual situación está el sindicalismo, sobre él se dijo:

"El sindicato, la cooperativa y el municipio, entre otros, son instrumentos fundamentales de desarrollo económico-social y perfeccionamiento democrático. Se debe proteger el derecho de sindicalización mediante garantías efectivas para sus afiliados y dirigentes y promoviendola contratación laboral colectiva. No hay democracia sin sindicalismo, ni sindicalismo sin democracia.”37

“El Partido respalda la acción responsable de los trabajadores en su lucha por el mejoramiento de su condición económica y social a través de las convenciones colectivas de trabajo, tanto en la empresa privada como en las instituciones públicas. A los sindicatos libres y democráticos corresponde en primer término la tarea de demandar los derechos y garantías a que se refiere este artículo, y también la creación del ambiente propicio para que el Estado, la colectividad y en su caso los patronos reconozcan estos derechos y garantías.”38

II. El Congreso Ideológico y los acercamientos del PLN: entre Vanguardia Popular y el Movimiento Costa Rica Libre.

Las conversaciones entre el PLN y Vanguardia Popular efectivamente se produjeron,

36 Ibid., página electrónica del Partido Liberación Nacional: http: // www. pln. or. cr/.

37 Ibid., página electrónica del Partido Liberación Nacional: http: // www. pln. or. cr/.

38 Ibid., página electrónica del Partido Liberación Nacional: http: // www. pln. or. cr/. 
pero no fructificaron. De la siguiente forma describe Jaime Cerdas parte de ese proceso y su desenlace:

"Años más tarde, cuando Figueres estaba en tratos con nosotros para la campaña de 1970, yo saqué ese tema (el Codo del Diablo), mientras tomábamos una taza de café en La Lucha, Luís Burstin, Figueres y yo. Mi reclamo no era que hubieran querido fusilarnos...Pero que luego del crimen Figueres hubiese justificado la muerte de gentes como Federico Picado, me parecía y me parece una complicidad imperdonable...Cuando le reclamé me miró...Más bien con una profunda tristeza...Se paró de la mesa y se fue a la orilla de la ventana, frente a una noche llena de neblina -'Errores don Jaime, errores. Yo se que los causa esa condenada manera de entender la amistad'. Fue la última vez que lo vi en privado. La siguiente fue cuando dio por terminado el arreglo con el partido, y nos dijo que el sabía que Vanguardia Popular estaba penetrado por CIA al más alto nivel”. ${ }^{39}$

La reunión con Figueres - referida por Jaime Cerdas- se celebró como se desprende de las afirmaciones de Eduardo Mora, cuando éste ostentaba la condición de candidato a la Presidencia de la República del Bloque de Obreros, Campesinos e intelectuales, él afirma:

“...me encontraba participando activamente, provincia por provincia...casa por casa...cuando recibí una invitación del candidato a la Presidencia de la República del Partido Liberación Nacional, don José Figueres, para sostener una conversación...En esta visita a la casa de don Pepe, por insinuación de él mismo, me acompañó Jaime Cerdas...Cuando nos referimos al Artículo 98 y a las restricciones antidemocráticas Figueres evadió la respuesta y, para hacerlo, volvió a ver a Cerdas y le preguntó si era zapatero; cuando éste le dijo que abogado, don Pepe le respondió: ‘Ah, yo creí que Rodolfo Guzmán era Zapatero’. “40

Este nuevo acercamiento entre el PLN y Vanguardia Popular, venía perfilándose antes de la realización del Congreso Ideológico. Esa posibilidad es anunciada por el propio Oduber al referirse a una eventual legalización del partido comunista. En Apuntes para un Congreso $39 \quad$ Cfr. Ver Ross, Marjorie. Memorias Jaime Cerdas Mora. La Otra Vanguardia. Editorial Universidad Estatal a Distancia. San José, Costa Rica. 1993.p. 176.

40 Cfr. Mora, Eduardo. 70 años de militancia comunista. Corporación Litográfica Nacional. San José, Costa Rica. p. 260. 
Ideológico del Partido Liberación Nacional, Oduber afirmó:

"La proscripción del Partido Comunista fue el castigo político a los que atropellaron la dignidad humana desde el Poder, de 1942 a 1948; quienes les dieron ese poder llevándolos al Gobierno durante esos seis años andan ahora de la mano de los grandes señorones de la política nacional. Nosotros somos diferentes de los comunistas, casualmente, porque respetamos la dignidad y los derechos políticos de todos los ciudadanos, y debemos discutir ampliamente el castigo aplicado; en ese sentido podría revisarse el artículo 98 de la Constitución Política, pero dejando firmes las medidas defensivas de nuestra democracia política, caso de que ellos deseen destruirla." ${ }^{\not 1}$

Oduber, oculta el interés electoral del PLN argumentando lo siguiente:

"Ojala que nuestros jóvenes tengan la posibilidad de presenciar en Costa Rica el debate diario con los comunistas, para que puedan verlos dando volteretas por todos lados, como los hemos podido ver nosotros. Así comprenderá mejor por qué su “revolución”, su “izquierda democrática”, es la Revolución Posible, la auténticamente costarricense. No la Revolución Imposible de los comunistas”. ${ }^{42}$

En igual sentido, en el Manifiesto de Patio de Agua se insinúa la posibilidad de la reincorporación de los comunistas a la vida política nacional, allí se dice: “240.Se debe mantener libertad a todos los ciudadanos para organizarse en partidos políticos sin restricciones ideológicas de cualquier género siempre que sus métodos de acción no sean la violencia.”³

El atractivo ejercido por Vanguardia Popular es explicable si tiene en cuenta la ausencia dentro de Liberación Nacional de una verdadera organización de su base social, salvo la Juventud Liberacionista. Esto resulta particularmente claro, en un documento preparado con vistas al Congreso Ideológico a realizarse en 1969, allí se puntualiza:

"Consideramos inconcebible que el PLN carezca de una sólida organización de sus fuerzas sociales: ni 41 Véase Oduber, Daniel. Op.cit., página electrónica del Partido Liberación Nacional: http: // www. pln. or. $\mathrm{cr} /$.

43

Ibid., página electrónica del Partido Liberación Nacional: http: // www. pln. or. cr/

Cfr. “Reestructuración del Partido Liberación Nacional”. Año 1968. En la página electrónica del Partido Liberación Nacional: http: // www. pln. or. cr/. 
campesinos organizados, ni obreros organizados, ni profesionales organizados, ni intelectuales organizados, ni mujeres organizadas. Ninguna fuerza social organizada. Debemos reconocer que solo la Juventud Liberacionista ha hecho un extraordinario esfuerzo en ese sentido, a pesar de la constante resistencia de la alta dirigencia: los jóvenes han dado una elemental lección de buena política a los dirigentes máximos”. ${ }^{44}$

Según Gerardo Contreras, Vanguardia Popular ya tenía a su haber, en esos años, los siguientes logros: "En 1966 y 1970 habíamos avanzado considerablemente en diferentes frentes; el frente campesino, el frente sindical se había logrado reconstruir la UTG en la zona sur, el Sindicato de la Unión de Trabajadores de Limón en el valle de la Estrella, el sindicato SITAGA o sea el Sindicato de los Trabajadores Agricultores y Ganaderos de Heredia, el Sindicato de Trabajadores de la provincia de Cartago... hay que destacar el gran esfuerzo que hace el partido desde el año 56 y 57 creando las juntas progresistas que hicieron un gran papel a nivel comunal... luego avanzamos en el frente estudiantil, hicimos esfuerzos en colegios por ganar gobiernos estudiantiles, en la Universidad en 1966 el partido y la Juventud Vanguardista Costarricense creamos el Frente de Acción Universitaria en el proceso por democratizar la Universidad de Costa Rica." 45

La primera plataforma electoral que inscribió Vanguardia fue el Bloque de Obreros, Campesinos e Intelectuales. Según Eduardo Mora, “(...) Ni con el Programa, ni con la bandera, ni con la dirigencia tratábamos de ocultar que el Bloque era la expresión electoral del Partido de los Comunistas" ${ }^{46}$ y se autodefinía a partir de los siguientes hechos: "El Bloque no es un Partido nuevo. Es un partido con una larga tradición de lucha, es el Partido de Manuel Mora; es el Partido que luchó en Costa Rica durante muchos años por los derechos del pueblo trabajador; es el Partido que luchó por las Garantías Sociales, por el Código de Trabajo; por alza de salarios; contra los altos impuestos y en fin por una transformación total del régimen social de nuestro país.”47

44 Ibid., página electrónica del Partido Liberación Nacional: http: // www. pln. or. cr/

45 Véase la entrevista hecha a Gerardo Contreras contenida en el documento "A los 75 años de la fundación del Partido Comunista de Costa Rica”. Junio 2006. En la página del Partido Vanguardia Popular: http: // www. vanguardiapopular. org/documentos/documentos.htm.

$46 \quad$ Ver Mora, Eduardo. Op. cit., p. 257

47

Cfr. Contreras, Gerardo. “Luisa González: una vida y una trayectoria consecuente”. Revista Comunicación, 
A través de los titulares de la prensa, puede observarse quién y cómo buscó que el Bloque fuera proscrito:

- Apelada inscripción del “Bloque”. El Partido Unión Cívico Revolucionaria apeló la resolución del Registro Civil por ordenar la inscripción del Bloque. (La Nación, 2 de Agosto de 1969, p. 21).

- Ciudadanos piden la nulidad del “Bloque” Un grupo de ciudadanos presentó ante el TSE un incidente de nulidad con relación al Bloque. ( Ibid., 6 de agosto de 1969, pp 33 y 37).

- Anulan al “Bloque” para las próximas elecciones ( Ibid., 13 agosto 1969, p. 93)

- FRANK MARSHALL: NO ESPERABA OTRA COSA DEL TRIBUNAL (Ibid., 14 de agosto de 1969, p. 18)

Sellada la suerte del Bloque3 se crea una nueva alternativa para sus seguidores, cuando Marcial Aguiluz ofrece el espacio del Partido acción Socialista, inscrito por él. Inclusive pone a la disposición los puestos en las papeletas para que fueran ocupados por comunistas. Efectivamente las papeletas fueron llenadas por estos. "48

“Casi terminado el año 1969 el PASO, anunció las candidaturas a diputados por San José de Manuel Mora Valverde, Secretario General del ilegal Partido de los comunistas, y de Marcial Aguiluz Orellana.”49 Marshall y el Movimiento Costa Rica Libre alzan nuevamente su bandera anticomunista, pero esta vez contra el PASO. El MCRL presentó una apelación ante el Tribunal Supremo de Elecciones con el fin de que se proscribiera el Partido Acción Socialista. Luego - de acuerdo con lo normado en el párrafo segundo del Articulo 98 de la Constitución Política- el

Volumen 15, año 27, No. 2, Agosto-Diciembre, Instituto Tecnológico de Costa Rica. Año 2006. p. 117. En la Dirección Web: http://www.itcr.ac.cr/revistacomunicacion/

$48 \quad$ Semanario Libertad, p.7.

$49 \quad$ Ver Mora, Eduardo. Op cit., p.259 
asunto pasó a ser examinado en la Asamblea Legislativa.

A esas alturas, el acercamiento entre el MCRL y el Partido Liberación Nacional se habían incrementado. Prueba de ello, son los campos pagados por ese Movimiento en los que fijan una posición más que favorable hacia Figueres, utilizando para ello su reconocida autoridad en lo que al "anticomunismo" se refiere. Así, en unos de espacios, afirman:

"Mientras José Figueres iba a la Habana a condenar la entrega de Fidel Castro al comunismo, Mario Echandi instruía a sus delegados para que se abstuvieran de combatir a Castro en la Conferencia de Cancilleres... Ciudadano: desconfié de los anticomunistas de última hora. Confié en el hombre que hecho a los comunistas del gobierno, y no en él que no hizo otra cosa en el gobierno más que coquetear con Fidel, vetar aguinaldos y negar alzas de salarios y aguzar las voces del odio” ( La Nación, 20 de enero de 1970, p.17).

Sin embargo, la cruzada anticomunista desplegada por el MCRL contra el PASO encontró no pocas resistencias en un importante sector de los diputados del PLN. En particular, puede citarse el caso de uno de los firmantes del Manifiesto de Patio de Agua: el Diputado Fernando Volio Jiménez.

No sólo la posibilidad de legalización de Vanguardia Popular, sino también la prohibición de agrupaciones de corte paramilitar tales como el MCRL, habían sido barajadas en el Manifiesto. En el Capítulo XXI “SEGURIDAD PUBLICA Y CIVILIDAD”, en aras de garantizar una saludable tendencia de la democracia costarricense en beneficio de la paz, se postularon distintas reformas legales y entre ellas la siguiente: “Que ha de prohibirse la existencia de todo tipo de organizaciones particulares de tendencia militar.”50

En ese Capítulo, además se enfatizó lo siguiente: a) “Que en un convenio continental solamente pueda comprometerse el país a organizar fuerzas militares costarricenses cuando haya un estado real de emergencia internacional, b)Que en caso de cumplimiento de convenios

50 Ver "Patio de Agua. Manifiesto Democrático para una Revolución Social”. Año 1968.En la página electrónica del Partido Liberación Nacional: http: // www. pln. or. cr/. 
internacionales, relacionados con situaciones bélicas, la contribución, de Costa Rica deberá estar restringida a ser de carácter humanitario y civil, c) Que en cuanto a los militares, de cierta graduación, en servicio regular, no duraran en sus puestos más de un período presidencial consecutivamente; no podrán pertenecer al Servicio Civil ni ser nombrados de nuevo, antes de otro periodo presidencial, después de haber cesado en sus funciones y d) Que no deberá operar en el territorio nacional ninguna misión militar de gobierno extranjero"51, entre otros aspectos.

Y en lo que refiere a la Guardia Civil -se advierte fundamentalmente- que estos cuerpos deben: a) "Eliminar de su seno todo resabio de militarismo, inclusive la nomenclatura", b) "Estar organizado dentro de una estructura de estricta civilidad” y c) "Recibir un adiestramiento exclusivamente policial y no militar, proporcional a su función de servicio de la comunidad en la represión del vicio y el desorden así como en la promoción del bienestar social.”52

Dos son las premisas sobre las que descansan las consideraciones anteriores. En primer lugar: "Es necesario mantener severamente, no solo en su letra sino también en su espíritu, las disposiciones constitucionales con relación al ejército”. En segundo lugar, “...el ejército en Costa Rica sólo se puede organizar pasajeramente, porque no puede existir un estado de emergencia que suponga la declaratoria indefinida de la defensa nacional ni un acuerdo continental que obligue a la creación permanente de fuerzas militares.”53

Según afirma Solís (1996), la Segunda Carta Fundamental del PLN constituyó “...un documento de consenso entre los grupos en pugna." ${ }^{54}$ En virtud de lo ya expuesto, la pregunta obligada resulta ser la siguiente: ¿cuáles razones explican el abandono en el Congreso Ideológico de las tesis defendidas en el Capítulo referido a la "SEGURIDAD PUBLICA Y CIVILIDAD” y , especialmente, de la prohibición en relación con la existencia de grupos paramilitares?

51 Ibid., página electrónica del Partido Liberación Nacional: http: // www. pln. or. cr/.

52 Ibid., página electrónica del Partido Liberación Nacional: http: // www. pln. or. cr/.

53 Ibid., página electrónica del Partido Liberación Nacional: http: // www. pln. or. cr/.

$54 \quad$ Cfr. Solís, Manuel. Op cit., p.360 
En principio, podría sostenerse que esa decisión tiene como telón de fondo, por un lado, un conjunto de intereses de carácter políticos-electorales inmediatos y, por otro lado, la necesidad imperiosa de garantizar la propia existencia del Partido Liberación Nacional y de su proyecto político, en un contexto nacional y latinoamericano en el que la democracia no constituye un valor de primer orden.

En particular, la transformación de Liberación Nacional en un Partido permanente e ideológico no está en contradicción con el propósito de “... salvar al liberacionismo de la derrota en 1970 y de la desintegración progresiva.” ${ }^{55}$ El acercamiento del PLN con el Movimiento Costa Rica Libre debe ser entendida como parte de esa consigna general. En efecto, con esta convergencia se persigue bloquear cualquier acusación de comunismo dirigida contra el PLN y, al mismo tiempo, incrementar la efectividad de la propaganda dirigida hacia Echandi y su partido.

Pero, este acercamiento significó en la práctica dejar fuera de toda consideración entendimientos con el Partido Vanguardia Popular. En buena medida, esto ya se observaba en el documento que se generó como producto del Congreso Ideológico: la Segunda Carta Fundamental del Partido Liberación Nacional (Marzo de 1969). En efecto, allí desaparece toda referencia al Capítulo XXI del Manifiesto y, en su lugar, en el Capítulo V de la Carta Fundamental, dedicado al tema de la Política Internacional, se alude parcialmente a una de las disposiciones del Manifiesto, a saber: "Que Costa Rica no podrá ser sede de congresos o agrupaciones militares, sean cuales fueren los motivos o causas de los mismos, ni aprovecharse de reuniones o conferencias de otra índole para celebrarlos”, pues en la Carta se señala lo siguiente: “Costa Rica no deberá ser sede de congresos o agrupaciones militares o paramilitares. ${ }^{, 56}$ En igual medida, en la Carta ya no quedan rastros de la posibilidad de legalizar el Partido de los comunistas.

A estas alturas, todavía subsiste la dificultad de incorporar en el análisis que hemos hecho

$55 \quad$ Véase el documento “Reestructuración del Partido Liberación Nacional”. Año 1968. En la página electrónica del Partido Liberación Nacional: http: // www. pln. or. cr/.

$56 \quad$ Véase "Segunda Carta Fundamental del Partido Liberación Nacional. Marzo de 1969.En la página electrónica del Partido Liberación Nacional: http: // www. pln. or. cr/. 
la polémica surgida entre un sector de Liberación Nacional y el Movimiento Costa Rica Libre en torno a la proscripción del Partido Acción Socialista. En otras palabras: ¿puede afirmarse con amplia certeza la ruptura definitiva entre Liberación Nacional y Vanguardia Popular a partir de la Segunda Carta Fundamental del PLN, a pesar de la defensa que un grupo de liberacionistas despliega alrededor del PASO?

La respuesta es afirmativa, pero implica una revisión tanto de los objetivos electorales de corto plazo del PLN como de lo que representa el Movimiento Costa Rica Libre y otras agrupaciones similares en la Costa Rica de los años 60, incluyendo, además, el factor nada despreciable de la creciente militarización de la Guardia Civil costarricense en clara obediencia a la política norteamericana hacia Centroamérica.

Empecemos por la posición que defendió Volio Jiménez en torno al PASO y la respectiva propaganda desplegada por el Partido Unificación Nacional. En líneas generales, el esfuerzo propagandístico del Partido de Echandi se enmarcó, en su etapa inicial, en el Manifiesto de Patio de Agua, subrayando nexos reales o imaginarios, entre Liberación Nacional y los comunistas, lo que resultó a la postre en un eje condenado al fracaso, tal y como se ven obligados a reconocer, sin decirlo abiertamente por supuesto, en el campo pagado del PUN que se reproduce a continuación:

"PARA APLICAR TODOS LOS PRINCIPIOS COMUNISTAS CONTENIDOS EN EL DOCUMENTO DE PATIO DE AGUA, LIBERACION NACIONAL NECESITA EN LA ASAMBLEA A MANUEL MORA Y A ARNOLDO FERRETO” ( La Nación, 30 de noviembre de 1969, p. 73)

Las intenciones de Fernando Volio Jiménez, habían sido descifradas pero ya muy tarde por Unificación Nacional. ¿Rehacer los ejes de su campaña y aprovechar la Segunda Carta Fundamental del PLN, estaba dentro de lo posible? En lo esencial, la respuesta es negativa, aunque es posible verificar algunos esfuerzos en el sentido de reorientar la campaña por parte del PUN.

En ese tanto, Volio Jiménez y quienes le acompañaron en la tarea encomendada por el Partido, cumplieron a cabalidad su misión. 
En un nivel de mayor profundidad, en la Carta Fundamental el no pronunciamiento respecto tanto al esquema de militarización introducido en nuestro país por los Estados Unidos como a uno de sus componentes centrales: el Movimiento Costa Rica Libre, tiene como trasfondo un conjunto de hechos centrales que abordan Figueres y Oduber, a saber:

- La guerra civil como parte del reino de lo posible.

Refiriéndose a la campaña de prensa, radio y televisión contra los bancos nacionalizados, Figueres advirtió lo siguiente:

1. “A nosotros se nos llevó a una guerra civil en 1948 con una propaganda parecida a la que ahora realiza la supuesta banca privada. Se nos llevó a combatir tres vicios de la Administración de entonces, que se daban por probados. la deshonestidad administrativa, y la alianza con el Partido Comunista".

2. "Veinte años después, algunas gentes que formaron parte de aquella gloriosa Oposición Nacional, y que crearon el clima de insurgencia contra los vicios de entonces, son aliados políticos de los supuestos o verdaderos delincuentes de ayer(...) Ambos grupos pretenden ahora acusarnos de los vicios políticos de ayer(...) Unos y otros olvidan que hay una gran diferencia entre la verdad y la mentira. La verdad es que en aquel tiempo hubo alguna corrupción, aunque fuera en grado menor de la que acusaban los detractores de ayer y aliados de hoy, que hubo fraude electoral en gran escala entre elecciones sucesivas, y que la mayoría de los adelantos sociales del período se debieron al Partido Comunista”. ${ }^{57}$

3. Cuando en Costa Rica se llegó a la violencia por otros motivos en 1948, hubo la suerte, lo digo sin modestias que los dirigentes éramos conscientes (...) Yo espero que mi generación no vuelva a verse envuelta en actos de fuerza. Pero van generaciones nuevas para arriba, y están descontentas. Se sienten frustradas. El ejemplo que ven en países vecinos no es bueno. Una campaña como la que se ha hecho contra un adelanto social realizado, es una provocación peligrosa...No faltará quien diga que lanzo amenazas...Lo que hago es advertencias, para quien se digne a oírlas. ${ }^{58}$

57 Ver Figueres, José. Op cit., págs. 116-117.

58 Ibid., págs. 118-119. 
- Fraude electoral ,corrupción administrativa y comunismo: los viejos móviles de la guerra civil en Costa Rica.

Por su parte, Oduber hace los siguientes señalamientos:

A. "Los vicios sociales que nos llevaron a la Guerra de Liberación Nacional han aparecido de nuevo en Costa Rica. El fraude electoral existió en las elecciones de 1958 y 1962 y, en gran escala, en 1966, aunque por diversas razones muchos dirigentes nuestros prefirieron callarse y no denunciarlo ante el país”.

B. "La corrupción administrativa es una carcoma de esta administración, y ya no hay negocio que se plantee al Gobierno o a ciertas instituciones, que se haga si no es a base de mordidas y comisiones. Fuertes intereses extranjeros compran funcionarios que les protejan y que hagan más segura su inversión. Los dirigentes destacados del Partido no deben callarse ante esos hechos. Los comunistas, con la mala fe que los caracteriza, quieren de nuevo penetrar el Estado costarricense para lo cual buscan el apoyo de los políticos”.

C. "El Partido no debe callarse ante estos hechos, porque si Liberación Nacional olvida su destino histórico, sellado con la sangre de compañeros caídos en las guerras, y no mantiene su lucha contra el fraude, contra la corrupción y contra el comunismo, con más energía cada vez, habrá abandonado sus banderas éticas y dictado su sentencia de muerte”. 59

En definitiva, más allá de las consideraciones electorales inmediatas las razones de fondo que explican la proximidad entre Liberación Nacional y el Movimiento Costa Rica Libre, están estrechamente asociadas con la caracterización que sobre éste último hace Manuel Mora Valverde en el sentido de que:

“El Departamento de Estado ha logrado crear organizaciones en nuestro país organizaciones que se dicen nacionales pero que no responden a los intereses de la Nación. Una de esas organizaciones, el 59 Véase Oduber, Daniel. Op cit., página electrónica del Partido Liberación Nacional: http: // www. pln. or. $\mathrm{cr} /$. 
llamado 'Movimiento Costa Rica Libre' está organizando un ejército privado con la anuencia de las autoridades. Ese ejército privado, financiado por los Estados Unidos, podrá a llegar a ser más poderoso que toda la fuerza armada de que dispone el Estado costarricense. Estará en condiciones de poner y quitar gobiernos". 60

En un momento, que soplaban vientos de guerra en Costa Rica, cuyo origen, a juicio de Oduber, tiene estrecha relación con la reaparición de los “viejos vicios sociales” que llevaron a la Revolución de 1948 y que para Figueres se relacionan con la destrucción anunciada de un “adelanto social”: la nacionalización bancaria, contar con un aliado político-militar como el Movimiento Costa Rica Libre era más que deseable para el PLN. Pero, esto le obligó a moderar sus reparos en lo que respecta a la militarización de la fuerza pública y de sus implicaciones sobre uno de los proclamados bastiones de la democracia costarricense: la paz. Aunque, en esa coyuntura, la fuerza pública militarizada no puede ser aprovechada por el PLN, su imperiosa necesidad se plantea respecto a futuros gobiernos liberacionistas, en un país donde las urnas no constituyen por definición el único medio de alcanzar y sostener el poder. En lo inmediato, con la fuerza pública, en teoría, del lado de Trejos Fernández y con el MCRL en condición de aliado del Partido Liberación Nacional, la posibilidad de una guerra civil quedó planteada.

Finalmente, la definición ideológica, plasmada en la Carta Fundamental del PLN, busca no colisionar con la política exterior norteamericana planteada hacia Centroamérica y Costa Rica. El PLN actuando en calidad de partido opositor y aspirante al poder, se inclinó por presentarse como aliado de la potencia del norte, primero, a través de su conformidad con el proceso de militarización experimentado por la fuerza pública costarricense y ,segundo, a partir de su acercamiento al MCRL. El “anticomunismo" se robusteció en el PLN a partir de esta toma de posición y, en consecuencia, entre el MCRL y los comunistas: prefirió a los primeros en calidad de aliados.

\section{REFLEXIONES FINALES}

El Manifiesto de Patio de Agua y la Carta Ideológica de la Juventud Liberacionista buscaron forzar una definición en lo ideológico del PLN, en aras de transitar de un partido 60 Cfr. Mora Valverde, Manuel. Op cit., p.529. 
en el que el personalismo ocupaba un lugar central hacia uno en la que la permanencia y una clara postura ideológica constituyeran sus rasgos más sobresalientes. El diagnóstico practicado en el Manifiesto reveló grandes insuficiencias en lo que refiere tanto a la democracia política como a la democracia económica. También puso de relieve la inconveniencia de la existencia de organizaciones de particulares de tendencia militar, así como de la creciente militarización de la Guardia Civil.

El Manifiesto plantea 'la ruptura con un sistema social que ya no garantiza el bien común y la instauración de un orden nuevo más apto para procurarlo”. Sus ideas fueron tildadas por Oduber de proclamas de "extrema izquierda" y las aprovechó el Partido Unificación Nacional para dirigir acusaciones de comunismo hacia el PLN. Sin embargo, la justeza de sus tesis obligó al PLN a aceptar muchas de ellas, aunque no con la profundidad con las que inicialmente fueron formuladas. Ese es el caso de la Reforma Agraria y lo relativo al Sindicalismo.

Privilegió, como instrumentos para alcanzar el “orden nuevo” tanto la organización popular como los partidos políticos, llegando incluso a defender -en el marco de la estricta libertad electoral- una posible legalización de Vanguardia Popular.

Los comunistas - tal y como se refleja en el programa planteado alrededor del Bloque- no estaban en capacidad de hacer planteamientos nuevos y se conformaban con enunciar sus logros en la década del 40. Pero, eran especialmente buscados cuando de procesos eleccionarios se trataba, por la enorme ascendencia que poseían sobre las esferas extraparlamentarias, condición que ni siquiera el partido más fuerte: Liberación Nacional podía mostrar a su favor. Pactó siempre en aras de recuperar su legalidad.

Pero, la reaparición de las causas que dieron origen a la Revolución del 48: fraude electoral, corrupción administrativa y comunismo, así como las amenazas que se cernían sobre la nacionalización bancaria, permitieron - a las máximas autoridades del PLN- ubicar la guerra civil como parte del reino de lo posible. Defender el texto y el espíritu de la Constitución Política en lo que al ejército refiere, postular la prohibición a la existencia de grupos paramilitares y abogar por la legalización del Partido Vanguardia Popular, constituiría un abierto desafió contra 
los Estados Unidos y la pérdida de un valioso aliado para un partido que había hecho suyo el presagio: de tener sus días contados.

Todos esos buenos propósitos fueron abandonados en el Congreso Ideológico celebrado en marzo de 1969, importó más garantizar la propia existencia del Partido Liberación Nacional y de su "proyecto político". El acercamiento con el MCRL le devolvió al PLN la tranquilidad perdida y le permitió repeler, en gran medida, las acusaciones de comunismo dirigidas hacia él por el Partido Unificación Nacional.

El episodio relativo a la defensa del Partido Acción Socialista por parte de un sector de Liberación Nacional ligado al Manifiesto de Patio de Agua, debe ser entendido simplemente como parte de una maniobra de carácter electoral destinada a confundir a los artífices de la campaña electoral del PUN, pues la reforma del Artículo 98 hubo de esperar hasta el año 1975.

El "anticomunismo" redefinido a partir de las concepciones de la política exterior norteamericana y del MCRL, se constituyó en uno de los fundamentos centrales de la ideología del PLN, quedando plasmado en la Segunda Carta Fundamental y fue desarrollado luego durante la Administración de Figueres Ferrer. 